\title{
Notas sobre el pensamiento trinitario de Tertuliano en Adversus Praxean
}

\author{
Sergio Zañartu \\ PROFESOR EMÉRITO \\ FACULTAD DE TEOLOGÍA \\ PONTIFICIA UNIVERSIDAD CATÓLICA DE CHILE \\ szanartu@puc.cl
}

Resumen: El autor pretende una presentación somera de los principales textos trinitarios del Adversus Praxean. Primero presenta estos textos por orden de aparición a través de la lógica de la obra para que queden bien contextuados en la polémica. Queda muy claro que el Sermo o Hijo es otra persona, distinta del Padre, pero no separado. Ambos son Dios, el único Dios, que tiene un Hijo sin romper la unidad. La segunda parte es más sistemática, centrada en vocablos claves que va recorriendo: monarquía y economía; las imágenes de sol, fuente y raíz; el uso de los números y la Trinidad; espíritu, persona y substancia. Finalmente se asoma a los orígenes del Sermo. Concluye que Tertuliano se mueve ortodoxamente dentro de la atmósfera subordinacionista prenicena.

Palabras clave: Monarquía, economía, persona, espíritu de Dios, substancia, prolación, subordinacionismo.

Abstract: This article studies the main trinitarian texts of Adversus Praxean in the same order of presentation so as to respect their context. Sermo and Son are clearly a person distinct from the Father but not separated form Him. Both are the unique God who has a Son who does not prevent the unity. Then it studies the main terms: monarchy and economy; the images like sun, source and root, the numbers and Trinity, spirit, person and substance. Tertulian is orthodox although in the subordinationist atmosphere before Nicea.

Keywords: Monarchy, economy, person, spirit of God, substance, prolatio, subordinationism. 
Pretendo una presentación del pensamiento trinitario de Tertuliano, como un primer acercamiento, en esta obra que es la obra clave de nuestro autor al respecto. El Adversus Praxean es una discusión implacable y seguida, a cuyo desarrollo lógico trataré de atenerme lo más posible para que queden bien contextuadas en él sus diversas afirmaciones atinentes a la doctrina trinitaria, a medida de que van apareciendo ${ }^{1}$. Volveré sobre ellas en forma más sistemática en la segunda parte de este artículo. En cuanto a las partes del discurso oratorio de Tertuliano, me atengo en general al índice de H. J. Sieben, en la huella de Uríbarri ${ }^{2}$. El elemento principal de la prueba son las citas bíblicas, una vez aclarados los conceptos centrales (praesumptiones) en los números 3 al 10. Mi ensayo será de pocas páginas, por tanto no hay que esperar que cada afirmación se pruebe con sus respectivos textos, ni mucho menos con todas las citas posibles de la Escritura. Quisiera ofrecer, por así decirlo, las principales líneas estructurales del pensamiento trinitario de nuestro autor, mostrando a la vez algo de su lógica. No pretendo una presentación completa, sino breve, siguiendo los tópicos que más me interesaron. Es un trabajo principalmente de lectura del texto, aunque vaya acompañado de alguna bibliografía. El texto de base es el texto crítico de G. Scarpat en su edición de $1985^{3}$. Las citas directas del texto las suelo poner en latín, conservando así, de mejor manera, el vigor del lenguaje de nuestro autor. Desde ya quiero aclarar que Spiritus (que en el texto suele ir con mayúscula), Spiritus Dei, muchas veces se refiere al Paráclito, Espíritu Santo, pero en bastantes otras a la substancia divina (Dios es Espíritu, según Jn 4, 24), que es poseída por el Sermo, el Hijo. Finalmente, el lector que busque ante todo una visión sintética, puede comenzar di-

Con frecuencia se trata de formulaciones trinitarias para explicar o resumir.

2 H. J. Sieben, Tertullian, Adversus Praxean. Lateinisch-Deutsch (Fontes Christiani 34, Herder, Freiburg 2001) 68-71 (en adelante, Sieben). Cf. G. Uríbarri BilbaO, "Arquitectura retórica del Adversus Praxean de Tertuliano", Estudios Eclesiásticos 70 (1995) 449-487;, G. Uríbarri Bilbao, “Tertuliano, Prax. 1-2. Una lectura con apoyo en la retórica clásica”, Estudios Eclesiásticos 71 (1996) 361-396.

3 G. Scarpat, Q. Septimii Florentis Tertulliani Adversus Praxean (Corona Patrum 12, Società Editrice Internazionale, Torino 1985) (en adelante SCARPAT). Entre las traducciones contamos también con una al castellano de J. Walker CruchagA, con introducción sobre los vocablos para expresar la generación del Sermo en Tertuliano, La generación del Verbo Divino en Tertuliano. Conceptos para un misterio. Estudio del Adversus Praxean, Tesis de Licenciatura en Teología Dogmática (Pont. Univ. Catol. de Chile, Santiago 1995). 
rectamente por la segunda parte de este artículo, reviniendo después a la primera, que es una contextualización más analítica de las diversas formulaciones a través de un recorrido del discurso de Tertuliano. Se trata, pues, de simple notas personales que puedan servir para introducir al lector en la mentalidad de este autor, remitiéndolo para un estudio acabado a sus grandes comentaristas, como E. Evans ${ }^{4}$, y a los estudios como el de J. Moingt ${ }^{5}$, R. Braun ${ }^{6}$, etc.

\section{LA lógica del Discurso de Tertuliano}

\section{Introducción (1-2)}

Esta obra corresponde al período montanista de Tertuliano ${ }^{7}$, por el año $213^{8}$, y nos deja entrever la culminación de su pensamiento trinitario. Se trata de una apasionada refutación de la reciente herejía de Praxeas", un monarquiano ${ }^{10}$ cerrado, a la manera judaica. Hasta ahora Tertuliano había combatido contra la idolatría pagana, contra valentinianos, marcionitas, Hermógenes, etc., en defensa del único Dios Creador. Pero ahora surge un ataque del otro lado, de los que en el futuro llegarán a ser modalistas, como Sabelio y discípulos ${ }^{11}$. Estos también defienden un

4 E. Evans, Tertullian's Treatise Against Praxeas. The text edited, with an Introduction, Translation, and Commentary, SPCK 1948, texto retomado por Wipf and Stock, Eugene (Oregon 2011) (en adelante, Evans).

5 J Moingt, Théologie Trinitaire de Tertullien (Théologie 68, 69, 70, 75, Aubier, Paris 1966, 1969). De aquí en adelante citado simplemente como Moingt. Libro clave que piensa, quizás demasiado a fondo, la teología de Tertuliano y sus términos.

6 R. BRAun, Deus Christianorum. Recherches sur le vocabulaire doctrinal de Tertullien (Études Augustiniennes, Paris ${ }^{2} 1977$ ).

7 Et nos quidem postea agnitio Paracleti atque defensio disiunxit a psychicis $(1,7)$.

8 Según H. P. BATUT, Pantocrator. "Dieu le Père tout-puissant" dans la théologie prénicéenne (Études Augustinienes, Antiquité 189, Paris 2009), 329, sería posterior al 217.

9 Praxeas o sus discípulos en Cartago.

10 Según G. Uríbarri Bilbao, Monarquía y Trinidad. El concepto teológico 'monarchia' en la controversia monarquiana ([Publicaciones Univ. Pont. Comillas Madrid I,62, UPCO, Madrid 1996]) 498, no es acertado designarlo como "monarquiano", porque justamente son los adversarios de los patripasianos, como Tertuliano, Novaciano y los dos Dionisios, los que defendieron la monarquía.

11 Cf. Moingt, I, 190-194. Unicum Dominum vindicat (diabolus), omnipotentem, mundi conditorem, ut et de unico haeresin faciat (1, 1). Monarchiam, inquiunt, tenemus $(3,2)$. 
único Dios Creador, pero no aceptan al Padre y al Hijo como distintos ${ }^{12}$. Por tanto, el Padre (idéntico con el Hijo) murió en la cruz ${ }^{13}$ : así fueron llamados 'patripassianos'. Para Tertuliano, esta es una gran herejía, una blasfemia intolerable. Dios es trascendente, omnipotente, invisible ${ }^{14}$, inmutable. El Padre, y el Hijo en cuanto Dios, ni siquiera pueden compadecerse. El Hijo ciertamente sufre y muere, pero en su bien 'distinguida' carne morta ${ }^{15}$. El Espíritu de Dios no podía, pues, sufrir en sí mismo. El sufrimiento es en el Hijo de Dios, pero en su carne (29, 1-7). Volvamos al desarrollo del discurso. Praxeas, pues, crucifica al Padre, defendiendo que el Padre y el Hijo son el mismo. Unicum Deum non alias putat credendum quam si ipsum eundemque et Patrem et Filium et Spiritum dicat $(2,3)$. Diríamos nosotros que no solo defiende un único Dios sino una única persona en Dios. Admitir una segunda persona en Dios, sería politeísmo para él. Unicum Dominum vindicat, omnipotentem, mundi conditorem ut et de unico haeresin faciat. Ipsum dicit Patrem descendisse in virginem, ipsum ex ea natum, ipsum passum, denique ipsum esse Iesum Christum (1, 1). Esto lo va refutando nuestro autor durante todo su tratado. Como en su estadía en Roma Praxeas echó para atrás el reconocimiento del montanismo ${ }^{16}$ por la Iglesia romana, exclama Tertuliano en 1, 5: Paracletum fugavit et Patrem crucifixit. Por lo demás, es de la fe judía sic unum Deum credere, ut filium adnumerare ei nolis et post Filium Spiritum $(31,1)^{17}$. Y la distinción trinitaria que trae el Nuevo Testamento ${ }^{18}$ tampoco es sostenida por los simples y rudos cristianos, que según Tertuliano son la mayoría (cf. 1, 6; 3, 1). La fe en Cristo también había sido atacada por los adopcionistas que negaban que Jesús fuera Dios. Frente a ellos, los monarquianos lo afirman tajantemente satisfaciendo

12 "Ses objections (contra Tertuliano) sont au nombre de quatre, et se groupent deux par deux: le reproche de détruire la monarchie, qui se prolonge dans l'accusation de trithéisme, et le refus d'admettre la substantialité du Sermo, qui aboutit à la suspicion de valentinisme”. Moingt, I, 204.

13 Y sería maldito por la ley.

14 Cf. p. e. 16, 6.

15 Non enim ex divina sed ex humana substantia mortuum dicimus (29, 3).

16 El Montanismo justamente destacaba al Espíritu.

17 "Tertullien a lui-même tenu à apposer la signature du Paraclet à sa doctrine trinitaire, et tout particulièrement à son usage du mot "économie»" (cf. 2, 1; 8, 5; 9, 3; 13, 5; 30, 5) Moingt, I, 112.

18 Sic Deus voluit novare sacramentum, ut nove unus crederetur per Filium et Spiritum, ut coram iam Deus in suis propriis nominibus et personis cognosceretur qui et retro per Filium et Spiritum praedicatus non intellegebatur $(31,2)$. 
así este aspecto de la piedad popular ${ }^{19}$. Otra nota de la herejía de Praxeas es que es reciente, a lo que nuestro autor opone, como siempre, la prescripción, y en este aspecto, después de presentar la regla de $\mathrm{fe}^{20}$, exclama: id esse verum quodcumque primum, id esse adulterum quodcumque posterius (2, 2; cf. 20,3). Tertuliano va a mostrar que evidentemente el Hijo es una persona distinta del Padre, sin romper por esto la unidad de la única substancia divina, su monarquía. Esto abarca también al Paráclito, Espíritu santo. Luego en Dios hay tres personas. Y al terminar la regla de la fe ha comentado: Quasi non sic quoque unus (Dios) sit omnia dum ex uno omnia per substantiae scilicet unitatem et nibilominus custodiatur oikonomiae (dispensación) sacramentum, quae unitatem in trinitatem disponit, tres dirigens Patrem et Filium et Spiritum, tres autem non statu sed gradu, nec substantia sed forma, nec potestate sed specie, unius autem substantiae et unius status et unius potestatis, quia unus Deus ex quo gradus isti et formae et species in nomina Patris et Filii et Spiritus sancti deputantur $(2,4)$. Así abre Tertuliano la gran perspectiva trinitaria de este tratado en que demostrará que el número no causa división.

Hasta aquí la Introducción (cap. 1 y 2). A continuación en esta investigación acompaño a Tertuliano párrafo tras párrafo hasta el final de la obra (cap. 31) mostrando lo trinitario en la 'nervadura' de su argumentación. Las ocho páginas y media que corresponde a esto han sido suprimidas en esta publicación para no exceder el límite de páginas que impone la revista para los artículos. Presento, pues, directamente la sin-

19 Similar a lo de Praxeas, la herejía de Noeto en el Contra Noetum de Hipólito 2, 3.7, se defiende declarando: si confieso a Cristo como Dios, él mismo debe ser el Padre, porque hay un solo Dios. Así se siente obligado a decir que el Padre padeció. Sobre la posible relación entre el Contra Noetum y el Adversus Praxean, puede verse, p. e., el resumen de Sieben (72-78). En una encuesta artesanal de los años 80 en sectores de las poblaciones de Santiago, me parecía encontrar una parecida claridad de la afirmación de la divinidad de Cristo, junto con un oscurecimiento de su distinción personal respecto al Padre.

20 Unicum quidem Deum credimus, sub hac tamen dispensatione quam oikonomiam dicimus, ut unici Dei sit et Filius, sermo ipsius qui ex ipso processerit, per quem omnia facta sunt et sine quo factum est nihil. Hunc missum a Padre in virginem ut ex ea natum, hominem et Deum, Filium hominis et Filium Dei et cognominatum Iesum Christum. Hunc passum, hunc mortuum et sepultum secundum scripturas et resuscitatum a Patre et in caelo resumptum sedere ad dexteram Patris, venturum iudicare vivos et mortuos. Qui exinde miserit secundum promissionem suam a Patre Spiritum sanctum, Paracletum, sanctificatorem fidei eorum qui credunt in Patrem et Filium et Spiritum sanctum $(2,1)$. Cf. De praescriptione, 13, 1-5; 36; De virg. vel., 1, 4 (3). 
tética visión de conjunto, que es la segunda parte y que se puede entender por sí misma.

\section{Aspectos de UnA Visión DE CONJUNTO DE LA TEOlOGía tRINITARIA EN ADVERSUS PRAXEAN ${ }^{21}$}

\section{a. La distinción de las personas}

El haber seguido hasta aquí el discurso de Tertuliano anotando las diversas expresiones que van apareciendo y con las que se esfuerza en ir expresando el dogma a través de toda su obra, nos permite ahora poder destacar algunas de esas expresiones habiendo ya tenido en cuenta sus contextos en la polémica. Pero, en general, solo seguiré algunas vetas significativas en busca de una síntesis. Sin embargo, aflorarán muchas repeticiones, que parecen inevitables en esta presentación, en parte dadas las continuas repeticiones del mismo Tertuliano en sus ideas y expresiones claves, y lo mucho que abarca su estilo conciso. Pero no volveré a insistir directamente en que el Hijo es otro (alius) respecto al Padre, ni en que la distinción es sin separación, etc. que son ejes de la argumentación de Tertuliano, ya vista con suficiente claridad ${ }^{22}$.

Toda su vida Tertuliano luchó por el único Dios Creador, contra los paganos, contra la gnosis y Marción, pero al final tuvo que luchar por la pluralidad en Dios en el Adversus Praxean, ante una nueva herejía, afirmando: tres personas. Está centrado en el Hijo y el Padre, pero también, aunque menos veces, incluye el Espíritu (Paráclito), siguiendo la regla de fe, la práctica bautismal. Toda su obra, como hemos visto, demuestra con evidencia meridiana que el Hijo de Dios, el Sermo, es un alius (distinto) del Padre. Y ese otro es también Dios, como se dice en la Escritura. Entonces, a juicio de los adversarios, nuestro autor se abriría al politeísmo al referirse a dos dioses, abandonando al único Dios. Pero no, Tertuliano solo afirma que Padre e Hijo, siendo ambos Dios, son dos, sin embargo, no dos dioses. Así nunca profiere dos dioses y dos

21 Sobre la presencia de algunos elementos filosóficos en el Adv. Prax., puede verse, por ejemplo, el resumen de SCARPaT, 108-112.

22 Que la distinción en Dios sea sin separación, lo va afirmando Tertuliano con diversos tipos de expresiones a través de toda su obra en unos 36 párrafos (numeración arábica), como se puede ir constatando en el resumen de la primera parte de este artículo. 
señores, no porque el Padre y el Hijo no sean Dios y tampoco el Espíritu no lo sea, y cada uno no sea Señor. Si antiguamente (en el A.T.) se llegó a predicar dos dioses y dos señores, fue para que cuando viniera Cristo este fuera reconocido como Dios y llamado Señor, porque es el Hijo de Dios y del Señor $(13,6)^{23}$.

A continuación, con las letras cursivas en castellano, iré señalando en este texto, cuál es el vocablo clave, que sirvió en los respectivos párrafos para el acopio de expresiones de nuestro autor en vista a clarificar los temas. Esos vocablos son: monarquía ${ }^{24}$ y economía; sol, fuente y raíz; segundo y tercero; tres y Trinidad; Paráclito y Espíritu; persona y substancia ${ }^{25}$. Tertuliano va a equilibrar la monarquía del único Dios, en que tanto insistían los adversarios, con la economía trinitaria, que ellos no admiten. Tertuliano les responde que, según el latín y el griego, 'monarquía’ solo significa un singular y único imperio, una dominación, pero no que sea necesariamente de uno solo, sin hijo ni administradores (3, 2). Si un hijo es asumido como participante, la monarquía sigue siendo principalmente de aquel de quien se comunica al hijo (son dos pero muy unidos). Según Dn 7, 10, la monarquía divina es administrada por tantísimas legiones y ejércitos de ángeles, tan ajenos a la substancia del Padre, ¡cuánto menos padecerá división y dispersión si el Hijo está en segundo lugar y el Espíritu Santo en tercero, siendo ambos tan consortes de la substancia del Padre! Porque una monarquía solo es destruida cuando sobreviene una otra dominación de la misma condición (status), que le es émula, contraria (3, 2-6). El verdadero Dios ciertamente es único, pero con su economía y disposición de la Trinidad: la unidad hace derivar de sí misma la Trinidad, que no la destruye sino la administra $(3,1$; cf. 2,4$)$. Se trata del sacramento de la economía. "Economia"

23 Son dos en cuanto Padre e Hijo, y esto no por separación de la substancia sino por disposición. Declaramos que el Hijo no está separado ni dividido (individuum) del Padre, no es otro por el estatus sino por el grado, y que aunque sea llamado Dios cuando se lo nombra aparte (singularis), no por lo tanto hace dos dioses sino un solo Dios (unum), porque él debe ser llamado Dios por la unidad con el Padre (19,8). Puede verse URíbarri, Monarquía y Trinidad, cap. 3.

25 No me detendré en otros vocablos como species, gradus, forma, proprietas, a los que Moingt dedica los capítulos cuarto y quinto de su tomo II, en relación a la particularidad y a la individualidad. Puede verse en SCARPAT, 84-98, un resumen del uso de los diversos términos del vocabulario trinitario; en D. Rankin, "Tertullian's Vocabulary of the Divine «Individuals» in Adversum Praxean" (Sacris Erudiri 40, 2001) 5-46. 
era el nombre de la dispensación expresada en la regla de la fe $(2,1)^{26}$. Por lo demás, el Hijo deriva (deduco) de la substancia del Padre y todo lo hace según la voluntad del Padre, de quien ha recibido toda potestad, ¿Cómo se puede destruir la monarquía que el mismo Padre le entregó? Esto también se aplica al tercer grado porque el Espíritu deriva del Padre por el Hijo. Actualmente la monarquía está en el Hijo, y en su estado va a ser restituida al Padre por el Hijo (1 Co 15, 24ss; Sal 109, 1) (4, 1-3). Aplicando al segundo y tercero de la Trinidad las comparaciones de la raíz, fuente y sol, declara que en nada es ajeno respecto a la matriz de la que trae sus propiedades, de manera que la Trinidad derivando (decurrens) del Padre por grados entrelazados y conectados, no contradiga nada de la monarquía y proteja el estatus de la economía $(8,7)$. Los monarquianos pretenden, contra la economía, que el Padre, el Hijo y el Espíritu son uno mismo, queriendo favorecer la monarquía, pero el Hijo no es otro por diversidad sino por distribución, no por división sino por distinción, por medida (modulo $)^{27}$.

El Padre enviará otro abogado, el Espíritu, Paráclito, mostrando en él el tercer grado, como el segundo en el Hijo, preservando la economía $(9,1.3)$. Sobre todo como discípulo del Paráclito, Tertuliano distingue a dos (no dos dioses), al Padre y al Hijo, y ya a tres con el Espíritu Santo, según el modo de la economía, que hace el número $(13,5)$. Lo contrario sería oscurecer toda la economía prevista y dispensada como objeto de fe $(13,6)^{28}$. Con todo, hay que observar la regla de fe, salvaguardando ciertamente la unicidad (unio) de la divinidad y el estatus de la monarquía $(20,1)$. Y termina afirmando nuestro autor: el hijo derramó el don recibido del Padre, el Espíritu Santo, tercer nombre de la divinidad y tercer grado de la majestad, predicador de la única monarquía e intérprete de la economía; y, para el que acoge las palabras de la nueva profecía, conductor a toda verdad, la que está en el Padre y Hijo y Espíritu

26 Hay que custodiar el sacramento de la economía, que dispone la unidad en Trinidad. (2, 4). Disposición y dispensación $(4,2)$. Un estudio a fondo sobre economía (manifestación histórica de la Trinidad) y disposición puede consultarse en Moingt, III, 5, especialmente pp. 929-932; véase I, 46).

27 El Padre es toda la substancia; el Hijo es una derivación, una porción del todo. El Padre es mayor $(9,2)$.

28 En la misma economía el Padre quiso que el Hijo estuviera en la tierra, desde donde suplicaba, y él en el cielo, lo que no es una separación (el Hijo junto con el Padre está en todas partes), sino una disposición divina $(23,4)$. 
Santo según el sacramento cristiano $(30,5)$. Lo que nos distingue de la fe judaica es creer en el único Dios agregando al Hijo y después al Espíritu. Porque el evangelio nos hace creer en los tres, que constituyen un solo Dios. De forma nueva, pues, es creído uno por el Hijo y el Espíritu. Dios, que predicado antes por el Hijo y el Espíritu no era entendido, ahora es conocido abiertamente en sus propios nombres ${ }^{29}$ y personas. Así Dios quiso renovar el sacramento $(31,1 s)$. El trabajo de Tertuliano será mostrar que el número no trae división en el único Dios (cf. 2, 4). Hasta aquí una breve síntesis sobre la complementaridad del uso de "monarquía y economía" según nuestro autor.

A menudo recurre a la ilustración del sol, la fuentey la raiz. La prolación (probolē) del Hijo por el Padre no separa sino custodia la unidad. Como enseña también el Paráclito, Dios profiere el Sermo, como la raíz el fruto, la fuente el río, el sol el rayo ${ }^{30}$, porque estas especies son prolaciones de aquellas substancias de las que proceden, son su progenie; con mayor razón el Sermo de Dios que recibe en propiedad el nombre de Hijo. Luego no se separa (discernitur) de su origen. El tercero respecto a Dios es el Espíritu, después del segundo, el Hijo, como el canal respecto al río de la fuente, etc. Son dos cosas, dos especies, dos formas, pero unidas (coniunctae), no divisibles (indivisae), coadhaerentes. No se es diverso (alienatur) de la matriz de la que se trae las propiedades (8, 5-7; cf. 22, 6). La distinción entre el Padre y el Hijo, permaneciendo la conjunción, la dispone en un número indiviso (individuum) de dos y tres, como

29 "Au cours de l'Adv. Praxean, Tertullien a lié de plus en plus étroitement la notion de «nom» et celle de "personne»", R. Braun, Deus Christianorum, 236. El nombre es garante de la individualidad.

30 Et nos autem sermonem atque rationem, itemque uirtutem, per quae omnia molitum deum ediximus, propriam substantiam spiritum adscribimus, cui et sermo insit pronuntianti, et ratio adsit disponenti, et uirtus praesit perficienti. Hunc ex deo prolatum dicimus, et prolatione generatum, et idcirco filium dei et deum dictum ex unitate substantiae: nam et deus spiritus. Etiam cum radius ex sole porrigitur, portio ex summa; sed sol erit in radio, quia solis est radius, nec separatur substantia, sed extenditur, ut lumen de lumine accensum. Manet integra et indefecta materia matrix, etsi plures inde traduces qualitatis mutueris... Ita de spiritu spiritus et de Deo Deus, modulo alter, numerum gradu, non statu, fecit et a matrice non recessit, sed excessit (Apologeticum, 21, 11-13). "La substancia divina no se divide, por tanto, sino que se extiende, y esto para esa misión específica que el Hijo ha de cumplir en la creación y redención del mundo”. A. GrillmeIER, Cristo en la tradición cristiana. I: Desde el tiempo apostólico hasta el concilio de Calcedonia (451) ([Verdad e Imagen 143, Sígueme, Salamanca 1997, traducido por M. Olasagasti G. de 3a ed.]) 271. 
los rayos del sol y el río de la fuente $(27,1)$. Así al rayo del sol, cuando está solo, lo llamo sol, pero no hablo de dos soles. El sol y su rayo son dos cosas, dos especies de una única e indivisible substancia $(13,10$ s cf. $18,4)$. Así como no podemos contemplar el sol en su substancia total en el cielo, pero toleramos el rayo según la temperatura de la porción que se alarga (inde porrigitur) a la tierra, así el Padre nos es invisible por la plenitud de la majestad, pero el Hijo es visible según la medida (modulo) de la derivación ${ }^{31}(14,3)$. Respecto a la imagen de la fuente y el río dice nuestro autor: La única substancia corre desde la fuente y no se separa (secernetur) de ella, sin embargo, por una turbulencia del río puede padecer el agua de la fuente, pero en el río (29, 6). Hasta aquí las ilustraciones. Así, con vocabulario diverso, durante toda su obra, Tertuliano sigue afirmando la distinción (otro), pero sin romper la indivisible unidad (unión). Porque sol y rayo son dos especies de una única e indivisible substancia, siendo el rayo una prolación de la substancia del sol, su progenie.

Entre los vocablos que usa para la distinción recientemente hemos topado con el segundo lugar para el Hijo y el tercero para el Espíritu. Aunque al Hijo le toque el segundo lugar y al Espíritu el tercero, esto no significa división ni dispersión porque son consortes de la substancia del Padre, a diferencia de los ángeles $(3,5)^{32}$. Es necesario que el Hijo por salir del Padre, le sea segundo ${ }^{33}$, lo que no significa separación; y si son tres, el Espíritu sea tercero respecto a Dios desde el Hijo (a Deo ex Filio, $e x$ en vez de $e t$, si seguimos el texto de Scarpat), como el fruto del tallo es el tercero respecto a la raíz, etc. $(8,7)^{34}$. En el Paráclito se muestra el tercer grado, como en el Hijo el segundo $(9,3)$ : así la Trinidad deriva del Padre por grados entrelazados y conectados $(8,7)$. El Hijo, que volverá

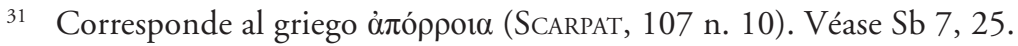

32 At ubi venit Christus et cognitus est a nobis quod ipse, qui numerum retro fecerat, factus <sit> secundus a Patre et cum Spiritu tertius, etiam Pater per ipsum plenius manifestatus, redactum est iam nomen Dei et Domini in unionem (unicidad)...ad unicum Deum... (13, 7).

33 Omnis origo parens est et omne quod ex origine profertur progenies est, multo magis sermo Dei qui etiam proprie nomen Filii accepit $(8,5)$.

34 Al llamarlo tercero, Tertuliano recalcó que viene por el Hijo. En 4, 1 sobre la no destrucción de la monarquía, expresa: Hoc mihi et in tertium gradum dictum est, quia Spiritum non aliunde puto quam a Patre per Filium $(4,1)$. Et tertia (persona) Spiritus in sermone $(12,3)$ es cotejado por Evans, ad l. c., con Orígenes, Comm. in Joa. 2, 76. 
de nuevo sobre la subes del cielo, derramó entretanto el don recibido del Padre, el Espíritu Santo, tercer nombre de la divinidad y tercer grado de la majestad $(30,5)$. En 12, 3 los llama segunda ${ }^{35}$ y tercera persona ${ }^{36}$, que adhieren al Padre. Estos números ordinales (grados) muestran, pues, una unidad 'jerarquizada', según la procedencia, en la derivación de la Trinidad $^{37}$.

Si nos fijamos en el número tres, en Dios, pues, son tres personas, Padre, Hijo y Espíritu, que hacen un Dios. Esto es la substancia del Nuevo Testamento, que sucede a la ley y los profetas. La renovación del sacramento es que Dios es creído único de manera nueva, por el Hijo y el Espíritu. Dios se ha hecho manifiesto para ser conocido en sus propios nombres y personas, el que antiguamente era predicado por el Hijo y el Espíritu sin ser entendido (31, 1s). El Hijo, después de su resurrección envió a los discípulos la promesa del Padre y finalmente mandó bautizar (ut tinguerent) en el Padre y el Hijo y el Espíritu Santo, y no en uno; no una sino tres veces, en cada nombre de cada persona $(26,9)$. El Paráclito toma de lo del Hijo, como este de lo del Padre y así la concatenación (connexus) del Padre con el Hijo y del Hijo con el Espíritu hace a tres co-adherentes, uno de otro. Los tres son uno (neutro: unidad de la substancia) y no uno (masculino, en singular) (Jn 10, 30) $(25,1)$. Tertuliano, pues, sostiene siempre la única substantia en tres coadherentes (12, 7). La economía dispone la unidad en Trinidad ${ }^{38}$ alineando (dirigens) a tres, al Padre y al Hijo y al Espíritu Santo, pero tres no por el estatus sino por el grado, no por la substancia sino por la forma, no por la potestad sino por la especie; sin embargo de una única substancia, estatus y potestad, porque es único el Dios, de quien estos grados, formas y especies son atribuidos a los nombres de Padre e Hijo y Espíritu Santo

35 Cf. 6, 1; 7, 5.9. Véase 5, 7; 13, 7.

Spiritus in sermone. En 11, 7: Spiritum loquentem ex tertia persona de Patre et Filio.

37 "Quand nous lisons qu'ils sont trois et qu'ils sont autres par le degré, nous ne devons pas entendre: selon un ordre temporel ou hiérarchique, mais: selon l'ordre ontologique dans lequel ils se communiquent la substance" MoINGT, II, 462.

38 "Le nombre de trois est le déploiement dans le temps des missions divines de la pluralité organique circonscrite à l'origine dans un seul des trois, le Père, de tel sorte que l'unité, «'épanchant d'elle-même en Trinité», se perpétue en maintenant le «nombre indivis». Cette explication se prolonge dans la visée du status: la divinité des trois est une et indivise, parce qu'elle a un seul príncipe originaire, le Père; c'est pourquoi la puissance dont il est la source, et qui est administrée par le Fils et l'Esprit, garde en eux sa forme monarchique" (MoINGT, III, 1082). 
$(2,4)$. Nuestro autor habla de tres, porque la verdad es una Trinidad razonablemente dispuesta (expensa) $(3,1)$. Tertuliano introduce el vocablo latino Trinitas; lo usa 9 veces en el Adv. Prax ${ }^{39}$. Así por ejemplo, en la creación del hombre, dada la unidad de la Trinidad ${ }^{40}$, el Padre habla en plural, como con sus ministros y testigos, con el Hijo que se revestirá de hombre y con el Espíritu que santificará al hombre (12, 3). Respecto entonces al número tres, son tres las personas que hacen un Dios. Existe una concatenación entre los tres, en que uno toma del otro. Existe, pues, una única substancia en tres coadherentes ${ }^{41}$.

Deteniéndonos en el Espíritu Santo, este es llamado Paráclito 11 veces. Praxeas, expulsando la profecía (el reconocimiento de los montanistas por Roma), puso en fuga al Paráclito ${ }^{42}$ (y crucificó al Padre); en

39 Todas las Escrituras nos muestran la evidencia de la Trinidad y su distinción (11, 4.9). En cambio el número "duo" estaría usado unas 52 veces en referencia al Padre y al Hijo (Dios y su Sermo), como deduzco del texto del CCL, E. Kroymann y E. Evans 1954, presentado por Library of Latin Texts. Los restantes estudios de vocablos en este trabajo se basarán normalmente en este instrumento.

40 Ligada en unidad simple $(12,1)$.

41 "Its positive values (de Adv. Prax. 3) lies in its recognition that the divine Father is the sole source from which the being of deity is derived. Tertullian's conception of the divine unity, on the other hand, rests on his doctrine of "economy», that the unity constitutes the triad out of its owm inherent nature, not by any process of sub-division, but by reason of a principle of constructive integration which the godhead essentially possesses. In other words, his idea of unity is not mathematical but philosophical; it is an organic unity, not an abstract, bare point”. G. L. Prestige, God in Patristic Thought (S. P. C. K., London $\left.{ }^{2} 1964\right)$ 99. Puede verse la conciliación entre unidad y Trinidad en Moingt, III, 778-796. "Mais tant qu'ils ne sont pas encoré apparus distinctement dans l'oeuvre de l'Économie, parce que la volonté naturelle divine de l'Économie n'a pas encore déployé la Trinité, le nombre n'apparaît pas encoré posé pour lui-même; et pour ce motif ils ne doivent pas être comptés ensemble comme faisant trois, selon le nombre cardinal qui additionne en somme des choses posées individuellement chacune pour soi. C'est pour quoi tous trois comptent alors pour un seul, étant plusieurs in uno, plusieurs dans un seul des trois, dans celui qui apparaît solus, le Père, lequel, contenant en soi un deuxième et un troisième, compte aussi bien pour plusieurs: sic quoque unus sit omnia, dum ex uno omnia". Moingt, III, ... 785. "A ce stade des origines donc, le nombre est réellement en Dieu, mais sous le mode d'y être présupposé, sous la forme d'une unité nombreuse, d'une pluralité enveloppée dans l'Un. Cet état ne peut pas être signifié comme un numerus énonçable par un chiffre cardinal; il ne peut non plus être désigné par le mot unio, qui signifierait la singularité; il est appelé unitas". Moingt, III 787. Véase Scarpat, 308; Braun, Deus Christianorum., 142-151.

42 Desisten de recibir los carismas (1, 5; cf. 1, 4). 
cambio Tertuliano lo reconoció y defendió, separándose de los psíquicos $(1,5.7)$. Es el que conduce a toda verdad, lo que Tertuliano, como más instruido por el Paráclito ${ }^{43}$, recuerda al comenzar la regla de fe en 2, 1. Según esta misma, es el prometido Espíritu Santo enviado por el Hijo (glorificado) desde el Padre, santificador de la fe de aquellos que creen en el Padre y el Hijo y el Espíritu Santo $(2,1)$. Es el otro abogado, que envía el Padre a ruegos del Hijo ${ }^{44}$, el Espíritu de la verdad, Paráclito en el tercer grado de la economía $(9,3)$.

Si nos fijamos ahora en el vocablo 'spiritus', unas 31 veces de $102^{45}$ parecería aplicado a la tercera persona de la trinidad recibiendo 9 veces el calificativo de 'sanctus' ${ }^{46}$. Así, como acabamos de ver a propósito del

43 Con la gracia de Dios para entender los tiempos y las intenciones (causas) de las Escrituras, siendo sobre todo discípulo, no de los hombres sino del Paráclito, determina Tertuliano al Padre y al Hijo y también tres con el Espíritu Santo según la economía $(13,5)$. Cf. 8,5 respecto a la prolación de la verdad.

44 "Otro" aplicado a la persona del Paráclito no significó división sino disposición $(9,3)$. Cf. 25, 1. Es otro porque toma de Cristo como este del Padre. Ita connexus Patris in Filio et Filii in Paracleto tres efficit cohaerentes, alterum ex altero... (25, 1).

45 Respecto a los otros usos, recordemos que Dios es Espíritu, lo que no obsta para que sea un cuerpo especial en su efigie (forma, cf. Flp 2, 6, véase SCARPAT ad 1. c.) $(7,8)$. Por así decirlo, el cuerpo del Sermo es Espíritu, porque él consiste (structus) en Espiritu (8, 4). El Espíritu de Dios (cf. vgr. 26, 5s; 27, 3.15), no directamente Dios, es la porción del todo que pasa (cessura) al nombre del Hijo $(26,3)$; es una cosa (res) substantiva, como porción del todo, que proviene de la substancia de Dios $(26,6)$. El espíritu es invisible, salvo en forma imaginaria (la visibilidad del Hijo en el A. T.) $(14,6)$; es el de la persona paterna, quien por la unidad es llamada su rostro (modelo) (14, 10). Cristo es el Hijo de Dios por su Espíritu (21, 12), según el Espíritu (Rm 1, 3s); en él contemplamos dos status (Dios y hombre); dos substancias, el Espíritu y la carne, unidas en una persona, pero no mezcladas en sus propiedades. Así el espíritu realiza sus poderes, obras y signos (27, 11; cf.27, 14; Jn 3, 6). Cristo es mortal en cuanto hombre, pero es inmortal en cuanto Espíritu $(29,2)$. El Espíritu de Dios, que está en el Hijo sufriente, no puede sufrir en su propio nombre $(29,7)$. El "Dios mío, ¿por qué me has abandonado" es una exclamación del hombre (carne y alma), pero no del Sermo ni del Espíritu (Dios), que muestra la impasibilidad (cf. 27, 6s; 29, 5s) de Dios al abandonar al Hijo en cuanto entrega a su hombre a la muerte $(30,2)$. Por lo demás el Hijo entregó su espíritu en las manos del Padre y así muere (30, 4; cf. 25, 2; 26, 9). En este uso amplio de la palabra Espíritu se debe en parte a que el "Espíritu de Dios" (Lc 1, 35) sea identificado con el Sermo (Jn 1, 14), el Hijo, y se aplique siempre a la segunda persona, salvo, al parecer, en $29,7$.

46 No incluyo el texto de 27, 4-6, porque según Tertuliano el que toma carne en Lc 1, 35 es el Espíritu de Dios, que es el mismo Sermo (cf. Jn 1, 14), cuya substancia 
Paráclito, la regla de la fe termina con la misión del Espíritu Santo, santificador de la fe trinitaria $(2,2)$. Son tres por el grado, forma y especie, pero de la única substancia, estatus y poder; proceden del (ex) único Dios (2, 4). El Hijo y el Espíritu Santo (segundo y tercer lugar) son consortes de la substancia del Padre $(3,5)$. Tercer grado para el Espíritu, porque viene del Padre por el Hijo $(4,1)$, a Deo ex $x^{47}$ Filio como el riachuelo que por el río viene de la fuente $(e x, a)$, etc. $(8,7)$. No se separan el uno del otro, aunque sean distintos (alius) $(9,1)^{48}$. El Padre enviará otro ${ }^{49}$ abogado, el Espíritu de la verdad Paráclito en tercer grado $(9,3)$. El Espíritu también habla en tercera persona sobre el Padre y el Hijo $(11,7.10)$. Así estos dichos exponen claramente la distinción en la Trinidad, estableciendo a cada persona en su propiedad. Habla también en plural en la creación del hombre, porque además de la adhesión del Hijo, su Sermo, al Padre, la tercera persona (estaba) en el Sermo y así el Padre hablaba con ambos como con sus ministros y testigos en la unidad de la Trinidad $(12,2 s)^{50}$. Inspeccionando la Escritura nuestro autor especifica a dos, Padre e Hijo, y ya a tres con el Espíritu Santo ${ }^{51}$, según la cuenta de la economía que hace el número $(13,5)^{52}$. El Espíritu es la promesa del Padre, enviado después de la resurrección, y el bautismo es en el Padre, Hijo y Espíritu Santo; tres veces se es bautizado según cada nombre de cada persona $(26,9)$. Derramó el don recibido del Padre, el Espíritu Santo, tercer nombre de la divinidad y tercer grado de la majestad, predicador de la única monarquía, pero intérprete de la economía,

es espíritu, siendo el Sermo la operación del espíritu, siendo ambos la misma cosa (unum) (26, 4s). Pero aplicándole el texto de Mt 1, 20.23 expresa: de Spiritu Sancto virgo concepit 27, 5). Véase, p. e. 26, 5.7. También refiere al Sermo el texto de 1 Co $2,11(8,4 ; 19,2)$.

47 Texto de Rosenmeyer en vez de et.

48 Non tamen diversitate alium Filium a Patre sed distributione, nec divisione alium sed distinctione, quia non sit idem Pater et Filius, vel modulo alius ab alio.

49 El Señor lo usó respecto a la persona del Paráclito, no significando división sino disposición (tercer grado).

50 El Espíritu es el que santifica al hombre, de quien se revestirá el Hijo. El hombre es hecho a imagen y semejanza del Hijo, quien es el verdadero hombre. Cristo en el Sermo asiste y administra la creación (12, 3-5). Todo fue hecho por el Sermo de Dios, que es otro a título de persona, no de substancia, para distinción, no para división. Por lo demás siempre sostengo una substancia en tres coadherentes $(12,5-7)$.

51 Cf. $13,7$.

52 El Padre, el Hijo y el Espíritu son Dios y Señor, pero no dioses ni señores (13, 6-8).

El Espíritu es el tercero. 
y si se admiten las palabras de la nueva profecía también conductor a toda verdad, que está en el Padre, el Hijo y el Espíritu Santo según el sacramento cristiano $(30,5)$. Frente a la fe judaica, lo propio es agregar al único Dios el Hijo y después del Hijo el Espíritu: Padre e Hijo y Espíritu, que constituyen un Dios. De tal manera que el uno, que antes era creído por el Hijo y el Espíritu, por los que era predicado pero no entendido, ahora sea conocido manifiestamente en sus propios nombres y personas $(31,1 s)$. Los confesores de la fe pueden sufrir, etc, porque el Espíritu de Dios está en ellos dándoles la posibilidad de sufrir $(29,7)$. En este uso de Paráclito y Espíritu es digno de notar que siempre están en contextos trinitarios. Es un otro, distinto (otro abogado), pero consorte, junto con el Hijo, de la substancia del Padre. Viene del Padre por el Hijo.

Tertuliano da el paso de llamar a los tres de la Trinidad, personas ${ }^{53}$. ¿En qué sentido? El vocablo "persona” es empleado 33 veces por Tertu-

53 Repecto al uso de persona por Tertuliano, entre otras cosas expresa Moingt: "Quant il passe à la démonstration de la pluralité divine par l'Écriture, Tertullien n'emploie plus ces mots (species, gradus, formae) que rarement, car ils sont plus propres à expliquer un mode d'être qu'à désigner un individu qu'on voit agir et qu'on entend parler. Il leur substitue un autre terme: persona. Il ne le tire pas de son vocabulaire philosophique, mais de son langage courant, qui lui donne volontiers une résonance juridique". Moingt, III, 1079s. "Le mot était familier à Tertullien pour désigner des individus, des personnages; cette notion juridique convenait à sa conception du Fils comme «fonctionnaire» de l'Économie divine; quelques écritures en suggéraient l'usage; l'exégèse l'y avait déjà accoutumé; enfin son idée philosophique de la personne, si courte qu'elle fût, pouvait s'appliquer au Fils, esprit, parole, interlocuteur de Dieu et libre exécuteur de ses volontés”. Moingt, II, 647. "Mais le sujet est toujours visé dans sa manifestation... Jamais il n'est visé dans le principe métaphysique de sa subsistence. Le mot (persona) désigne bien l'individu subsistant. Le concept ne signifie pas par lui-même et directement, comme il le fera chez Boèce, l'individua subsistentia". MoINGT, II, 645. "La réprésentation de l'étendue, qu'il n'a pas su abstraire du concept de substance et qui quantifie le degré de subsistance, ainsi que nous l'avions signalé, se réfléchit sur le concept de personne et celle-ci, trop immergée dans le corpus, trop assujettie à ses délimitations, ne réussit pas à se poser comme le pur acte de subsister individuellement". Moingt, II, 644. "Son principal titre de gloire restera d'avoir opposé l'unité de la substance à la trinité des Personnes”. Moingt, II, 646. "Dans son registre philosophique Tertullien trouvait substantia au niveau de la conception, et l'y a fortement maintenu dans son usage trinitaire; y a élevé au même degré species et forma, qu'il utilisait d'ordinaire dans un sens plus physique que métaphysique, mais pourtant philosophique; il a laissé le mot persona où il se 
liano. Para distinguir las personas, nuestro autor se fija en las diferentes voces en el texto bíblico. Tantas personas cuantas voces (cf. 23, 4). En la Escritura se habla ex persona ${ }^{54}$; así el Espíritu habla en tercera persona del Padre y del Hijo (Sal 109, 1, etc.) (11, 7s). Casi todos los salmos "soportan" (sustinent) la persona de Cristo ${ }^{55}$, representan al Hijo hablando al Padre $(11,7)$. Hasta aquí con pocas citas expone Tertuliano claramente la distinción de la Trinidad ${ }^{56}$. Y así también el resto, ya del Padre sobre el Hijo o al Hijo, ya del Hijo sobre el Padre o al Padre, ya del Espíritu: constituye a cada persona en su propiedad (cf. 11, 9s). Los textos numerosos de la que llamamos exégesis prosopográfica (quién habla, de qué habla y a quién habla) presentan, pues, claramente la Trinidad y su distinción. Por otra parte, Dios sería mentiroso si siendo él mismo su propio Hijo, atribuya a otro la persona del Hijo $(11,4)^{57}$. El plural sumus unum de Jn 10, 30 no ha sido dicho a partir de la persona de uno

trouvait: au niveau de la perception”. MoINGT 647. "Il (Tertuliano) voit la nécessité de concevoir le Sermo d'une part comme substantia, pour affirmer sa réalité, d'autre part comme persona, pour exprimer sa distinction réelle. Mais il voit en même temps qu'il ne doit pas en faire une substantia personalis, pour ne pas le «situer à l'extérieur de Dieu» et ne pas diviser la substance divine. Il reprend donc le mot persona, dont il avait par ailleurs une longue habitude. D'une part il l'associe à res, et indirectement à forma et species, pour montrer la consistance de l'individu; d'autre part à gradus et aux adjectifs numéraux, pour montrer que l'un se tient dans l'autre, d'où il provient, sans que la pluralité des personnes ne morcelle la substance divine. Ainsi crée-t-il (avec les réserves antérieures) la formule: una substantia in tribus (personis) cohaerentibus". MoINGT, 668. "Quant il veut prouver la réalité du Sermo, il considère la substance rationnelle, l'esprit substantiel de Dieu. Quand il veut prouver sa distinction, il considére le personage du Fils, celui que l'Écriture montre en rapports avec d'autres". MoINGT, 670. Moingt ya había precisado su intento en Théologie, I, 40 respecto al uso de persona por Tertuliano. Puede verse la síntesis de A. Milano, Persona in teologia. Alle origini del significato di persona nel cristianesimo antico (Saggi e Ricerche, 1, ed. Dehoniane, Napoli 1984) 65ss. En 13, 2 ad personam.

55 En una exégesis prosopográfica (Sieben, ad 1. c.). "Persona, quindi, oscilla tra il significato grammaticale e teatrale, soprattutto nell'esegesi dei passi veterotestamentari dove le persone divine sono meno decisamente definite, al significato di 'personaggio reale e concreto' quale si prestava ad essere il Cristo del Vangelo, operante in determinate circostanze di tempo e di luogo. Il ragionamento di Tertuliano tende continuamente a portare il primo valore di persona al secondo" (SCARPAT, 89).

57 Cristo es el espíritu de la persona paterna, quien es la persona mayor (cf. 14, 9s), la primera en ser conocida $(18,2)$. 
solo $(22,10)$. La voz de Jn 12, 28 era para que creyeran en el Padre y el Hijo, cada uno en sus nombres, personas y lugares $(23,7)$. Que el Padre esté en el cielo y el Hijo en la tierra, conforme a Mt 16, 16s, establece la distinción de ambas personas $(21,5)^{58}$. Si en las escrituras se hubiere encontrado que la persona de Dios y Señor es una única, Cristo no sería ni Dios ni Señor (cf. 13, 6). Y respecto a la persona (in persona) del Paráclito, el Señor usó el mismo término alius (Jn 14, 16) significando no división sino disposición (tercer grado) $(9,3)$. Al decir "yo estoy en el Padre y el Padre en mí" (por los prodigios y la doctrina) se manifiesta la propiedad de cada una de ambas personas $(24,9)^{59}$. El resucitado manda finalmente que se bauticen en el Padre y el Hijo y el Espíritu Santo, y no en uno. Porque somos bautizados no una vez sino tres a cada nombre en cada persona singular $(26,9)$.

La sabiduría había sido creada (conditam) como segunda persona, generándola Dios en su mente (sensu) $(\operatorname{Pr} 8,22.25)(6,1)$. Asistía a Dios en la creación, quien se gozaba con ella, y ella se deleitaba en la persona de él $(\operatorname{Pr} 8,30)(6,2)^{60}$. Y el Padre habló en plural en la creación del hombre porque se le agregaba la segunda y tercera persona $(12,3)^{61}$. Y en las obras anteriores al mundo, uno es el Dios que dice y otro el que hace, otro a título de persona (nomine personae) no de substancia, para distinción y no para división $(12,6)$. Diríamos nosotros, la persona distingue pero no divide, porque no es otra substancia. A la pregunta del contrincante de si atribuye alguna substancia al Sermo, constituido de espíritu, sabiduría y razón, responde que por supuesto: es en realidad algo subsistente (substantivum) ${ }^{62}$ por la propiedad de la substancia, porque puede ser vista como una cosa y una cierta persona, y, así constituido el segundo después de Dios, hace que sean dos: Padre e Hijo, Dios y Sermo. No es un sonido de la boca, inteligible al oído, algo vacío, inane, incorporal. No puede carecer de substancia lo que procedió de una

58 Cf. 15, 1 (distinción manifiesta y personal entre el Dios visible y el invisible).

59 El Padre se hace visible en el Hijo por sus prodigios y no por la "representación" de la persona $(24,6)$. Jn 14, 10 declara la conjunción manifiesta de las dos personas para que no fuera deseada la presencia del Padre aparte como visible y tener al Hijo como "representante" del Padre (24, 8, según el texto de SCARPAT).

60 El Padre, gozándose del Hijo, quien a su vez se goza en la persona de él, le dice: "tú eres mi hijo, yo te he engendrado hoy" (Sal 2, 7), etc. $(7,2)$. Así también el Hijo ex sua persona confiesa al Padre $(\operatorname{Pr} 8,22.25)(7,3)$.

61 Dios hizo al hombre a imagen de Dios (Hijo) (distingue entre las personas) (12, 4).

${ }^{62}$ Cf. 26, 6. No es accidente, como la virtus Altissimi o la providencia. 
substancia tan grande y que hizo tantas substancias. Dios todo lo hizo por él, lo sólido, lo pleno, lo corporal. Luego no puede ser vacío e inane. Y es llamado Dios (Jn 1, 1; Flp 2, 6). Y Dios, aunque sea espíritu, es cuerpo $^{63}$. Tertuliano concluye así esta argumentación: Quaecumque ergo substantia sermonis fuit, illam dico personam et illi nomen Filii vindico et, dum Filium agnosco, secundum a Patre defendo (7, 5-9).

Finalmente, los adversarios no pudiendo negar la distinción entre el Padre y el Hijo, admiten la distinción, pero en una única persona: el Hijo es carne, hombre, Jesús; pero también es Padre, Espíritu, Dios, Cristo $(27,1)$. Tertuliano, en cambio, en referencia a la encarnación del Hijo, afirma que el Sermo (inmutable como Dios) no se transfigura en carne sino se reviste de ella, es Dios y hombre sin mezcla de substancias $(27,6-10)$. Y añade: vemos un doble estatus, no confundido sino unido en una persona ${ }^{64}$, Dios y el hombre Jesús, a tal punto conservada la propiedad de cada substancia que el Espíritu hace en él los prodigios, obras y signos y la carne ejecuta las pasiones: hambre, sed, llanto, angustia, muerte $(27,11)^{65}$. Así ha respondido nuestro autor a la aplicación que hacen los herejes de 'una persona' al Padre (Espíritu) y al Hijo (carne) en Jesucristo para salvar su tesis monarquiana. Y concluyendo el tratado, afirma nuestro autor que Dios ha renovado el misterio: el único Dios es creído ahora por el Hijo y el Espíritu, conocido en sus propios nombres y personas. Antes (A. T.) era predicado por el Hijo y el Espíritu, pero no se comprendía $(31,2)$.

En esta revisión de los textos con el término "persona" hemos encontrado una buena base prosopográfica, pero, como toda la obra de Tertuliano, en búsqueda del otro, del que no puede ser el mismo. Por tanto, la persona es un otro, y un otro racional en el misterio de Dios. Siempre ${ }^{66}$

63 Cf. F. Urfels, "Le corps de Dieu. Une lecture de l'Adversus Praxean VII, 6-9", NRT 131 (2009) 600-613.

64 Moingt II, 639 traduce: “dans une seule personne: Jésus, Dieu et Homme”. Según R. Cantalamessa, La cristología de Tertulliano, (Paradosis 18, Univ. Frib. Svizzera, Friburgo 1962) 168-176; R. CAnTAlamessa, La cristología de Tertulliano... "Tertullien et la formule christologique de Chalcédoine", (StudPatrist 9, Akademie, Berlin 1966) 139-150, el uso de persona sigue siendo el Trinitario. Cf. Sieben, 8790. Ya había expresado: Filius hominis est, per carnem scilicet, sicut et Filius Dei per Spiritum eius (21, 12; cf. 27, 10.14).

65 Cf. De carne Christi, 5, 7s.

66 El único texto en que "persona” no se aplica directamente a este misterio es el ejemplo de 3,2 , en que se refiere a los próximos, como "oficiales" de la monarquía. 
implica una referencia a otras personas (con sus propiedades), implica pluralidad ${ }^{67}$, salvo en boca de los herejes ${ }^{68}$, y en relación al Sermo encarnado $(27,11)$. ¿Qué consistencia tiene la persona, por ejemplo, la persona del Sermo? La de la realidad; es substantiva (subsistente) ${ }^{69}$. Diríamos que si es Dios, es substancia. Tiene la substancia del que la emitió (7, $5-9)^{70}$. Su consistencia aparece clara, entre otras cosas, en la forma de bautizar en cada uno, o en la persona una del Sermo que se revistió de carne, y fue crucificado ${ }^{71}$. Pero esto no excluye que haya un orden entre las personas, como vimos a propósito del número. El Espíritu viene del Padre por el Hijo. Las tres personas hacen un Dios, pero son tres especies concatenadas (en que una toma de la otra) de la única e indivisible substancia. Por los documentos que tenemos, Tertuliano sería el primero en usar "persona" en relación a la distinción trinitaria. Esta palabra y su profundización, va a tener un gran futuro hasta nuestros días, aunque algún contemporáneo haya destacado que no es la mejor. Pero las otras palabras para decir los dos o tres en Dios, como "grado" (8 veces), "for-

67 J. Hilberath destaca su aspecto relacional. Se expresa así: “ "Selbstand in Relation» scheint mir eine angemessene Umschreibung des von Tertullian verwendeten Personsbegriffs zu sein, eine philosophische Definition, ein Auf-den BegriffBringen des phänomenologischen Befundes, dass Person der unersetzbare Träger einer unverwechselbaren Rolle in einem interpersonalen und interaktionären Rollenspiel ist", Der Personbegriff der Trinitätstheologie in Rückfrage von Karl Rahner zu Tertullians "Adversus Praxean", (Innsbrucker theologische Studien 17, Tyrolia, Innsbruck-Wien 1986) 231. "Für die (unserem Denken immer nur in Grenzen mögliche) Lösung des trinitätstheologishen Grundproblems von Einheit und Verschiedenheit hat er reinen Ansatz aufgezeit, der in einer personal-relationalen Ontologie überzeugend ausgebaut werden könnte" ( J. Hilberath, Der Personbegriff der ... 294). Puede verse la recensiónn crítica de K. H. Neufeld y su pequeña polémica, en ZKTh 110 (1988) 313-322, centrada en la interpretación de Rahner. 27, 1. Cf. 13, 6 .

69 No es un simple nombre. Pero no por eso otra substancia, lo que expresaría dos dioses. La distinción es por la persona, pero no por la substancia, lo que implicaría división $(12,6)$. "Dans l'intention de soutenir la distinction réelle du Père et du Fils, il a reconnu au Sermo le caractère de la substantialité: la consistance d'un corpus distingué par son effigies. Il en a conclu que le Sermo est une chose particulière, res, res substantiva: une chose que existe individuellement dans une substance. Pour se défendre de diviser la Monarchie, il a affirmé l'unité de substance du Père et du Fils et de l'Esprit". Moingt, II, 430.

70 Como ya vimos en las ilustraciones físicas, por ejemplo, como el agua del río respecto a su fuente, etc. Hay un mutuo gozarse de Dios y la sabiduría, del Padre y del Hijo $(6,2 ; 7,2)$.

71 Y no el Padre. Y el Espíritu, Paráclito, tiene la consistencia del otro abogado. 
ma” (unas 3 veces), "especie" (unas 5 veces), que Tertuliano siempre usa en sus tentativas contraponiéndolas a expresiones unitarias ${ }^{72}$, no han corrido la misma suerte. En esta parte de nuestro artículo en busca de la distinción, aunque siempre nuestro autor va contrapesando con afirmaciones respecto a la unidad, recorrimos antes lo referente al uso de economía, a las ilustraciones físicas, al número, al Paráclito y al Espíritu, lo que para esta visión de conjunto nos parece suficiente por mientras. Pero ¿cómo expresa conceptualmente la unidad del único Dios, en la que ha venido insistiendo siempre?

\section{b. La unidad de la subtancia}

Aunque ya ha aparecido mucho material sobre la unidad y sobre las personas distintas en la economía, que en general no volveré a aludir, ahora me detendré en un vocablo central del tema de la unidad, el de substancia, como antes lo hice en "persona". Lo usa 46 veces en esta su obra, pero aplicado al Dios trinitario solo unas $26^{73}$. Comencemos por las fórmulas en cierto sentido estáticas y más igualitarias, que con todo, en sus contextos inmediatos suelen estar compensadas por otras expresiones más dinámicas. Los tres no se diferencian por la substancia (estatus ${ }^{74}$,

72 En 2, 4 las contrapone a estatus, substancia, potestad.

73 Véase Scarpat, 93-95; Moingt, II, 391-396.

74 Sobre el uso de status puede verse el buen ensayo de J. Moingt, "Le problème du Dieu unique chez Tertullien”, (RevSR 44 1970) 337-362, pp. 350ss. El status depende del origen. Considerando citas de Adv. Herm., como de 4, 1; 51, y de Adv. Marc., como I, 3, 2; 7, 3; 22, 3, afirma Moingt, "Le problème du Dieu... 353: "C'est de cette même origine (status) que Dieu tient sa condition (status) d'être souverainement grand, et 'tout ce qui est naturel en lui doit être aussi inengendré (=sans commencement temporel), pour être éternel, conformement à son origine (statum)". "L'usage du mot status vise donc à exclure un nombre originaire de principes constitutifs de la divinité. Ce principe unique est le Père, lequel, avant de se manifester dans sa distinction de Père, contenait en lui seul, comme un seul Dieu, tout ce par quoi le Fils et l'Esprit existent et sont constitués Dieu [...] En vertu de cette unicité d'origine, les trois sont d'une seule substance, c'est-à dire de la substance d'un seul, de celui qui est le principe originant; il en va de même pour la puissance, qui est la relation de la divinité au monde." Moingt, "Le problème du Dieu ... 359s. Respecto a "Dios único", había dicho este autor que para Boecio será un «nom abstrait et commun de l' essence, qui n’inclut pas la particularité de l'existence, et là (para Tertuliano) nom concret et propre d'un individu, bien personnalisé par la possession solitaire du pouvoir, un monarque (el Padre) [...] En bref, le problème de Boèce, c'est d'expliquer que la divinité qui est en chacun des trois est numériquement la même, celle de l'essence commune; pour Tertullien, 
potestad), que es única $(2,4)^{75}$. La única substancia está en tres que coadhieren a ella $(12,7)$. El Hijo en su propio nombre también es invisible (como el Padre), en cuanto Sermo y Espíritu de Dios, por la condición de la substancia y por ser Dios $(14,6)$. Dios y el Sermo, el Padre y el Hijo, son dos res, dos especies de una única e indivisible substancia (13, 10). Nos introduce en una forma más dinámica la imagen del agua, única substancia, que corre desde la fuente, de la que no se separa, y en el río padece injuria $(29,6)$. La substancia es la del Padre. Así el Hijo y el Espíritu Santo son consortes de la substancia del Padre (3, 5). El Hijo viene de la substancia del Padre sin destruir la monarquía que le ha sido entregada $(4,1)$. La prolación (probola) del Hijo por el Padre es como la del fruto por la raíz, del río por la fuente, del rayo por sol: prolaciones de las substancias de las que proceden, de las que no se $\operatorname{separan}^{76}(8,5)$. El Sermo es un otro, por la persona y no por la substancia, para distinción y no para división $(12,6)$. El Padre y el Hijo no son dos dioses y señores, porque son dos, no por la separación de la substancia, sino por la disposición, porque el Hijo es indivisible e inseparable del Padre. Es otro por el grado, no por el estatus, y, si individualmente es llamado Dios, no hace dos dioses sino uno solo, porque es llamado Dios por la unidad con el Padre $(19,8)$.

De estas citas, y de algunas anteriores, concluimos que la substancia de Dios es única, y según 27, 6s, Dios es inmutable, porque Dios es eterno $^{77}$. El Hijo no tiene otra substancia, no es otro Dios, sino que recibe del Padre la misma substancia, que por medio de él pasa al Espí$\mathrm{ritu}^{78}$. Esta es la conexión, la concatenación, el despliegue (disposición, distribución) de la economía respecto a la monarquía del Padre. El Pa-

c'est de montrer que le pouvoir qui est en chacun des trois est numériquement le même, celui d'un seul des trois, le Père tout puissant" Moingt, "Le problème du Dieu ... 351s.

75 Cristo y el Padre son unum (Jn 10, 30) por la unidad de la substancia $(25,1)$; son tres cohaerentes, alterum ex altero (conectados). Véase 8, 6. No hay separación de la substancia sino disposición $(19,8)$.

76 Progenie del origen.

77 El Padre y el Hijo por su condición de Dios son impasibles (29, 5s). La eternidad es lo propio de Dios (p. e. Adv Hermog 4, 1; Adv Marc I, 3, 2).

78 Cf. 4, 1; 8, 7. Añade que en nada es ajeno a la matriz, de donde trae sus propiedades. Así la Trinidad deriva (decurrens) del Padre por grados entrelazados y conectados $(8,7)$. Como ya vimos, el agua también (única substancia) derivaba (decurrat) de la fuente y no se separaba de ella $(29,6)$. 
dre obviamente es el mayor ${ }^{79}$, porque de él viene el Hijo, su progenie, unigénito, tan Dios como él. Iluminando estas expresiones las imágenes físicas son como de derivación. Por esto, como vimos en la aplicación de números ordinales, hay un segundo y un tercer grado en Dios. Pero fuera de la derivación, ¿`cuál es la diferencia entre las personas respecto a la substancia ${ }^{80}$ ? Nos dice 26, 6 que el Espíritu de Dios (se refiere al Sermo), como realidad substantiva ${ }^{81}$, el mismo no es Dios sino que lo es en cuanto proviene de la substancia del mismo Dios ${ }^{82}$. Por eso es una realidad substantiva y como una 'porción' del todo. Según 9, 2, el Padre es toda la substancia, el Hijo, en cambio una derivatio ${ }^{83}$ totius et portio $^{84}$, porque el Padre es mayor. El Hijo es otro según la medida

79 La monarquía es principaliter de aquel de quien se comunica al Hijo, es decir del Padre (cf. 3, 3).

80 “Considéré maintenant en tant qu'il est ce subsistant particulier issu du Père et dans son acte même de subsister, le Fils ne subsiste pas avec la même plénitude et souveraineté, indépendance et liberté que le Père. Car le subsister du Père est l'acte d'un sujet qui se pose de lui-même dans sa substance; et celui du Fils, le fait d'un objet qui est posé dans une substance et par elle, ou encoré le fait dans un sujet qui dans son acte même d'être soi se trouve assujettie à un autre. Car le Père est la substance divine. Il en revendique la totalité comme son bien propre, et il s'attribue en elle la possession de cette partie de lui-même qu'il communique au Fils; tandis que le Fils est une chose de cette substance et ne peut ni s'attribuer la totalité dont il est une partie ni même revendiquer sur cette partie un plein droit de propiété [...] Au plan de l'en soi, il se montre identique au Père parce que le Père, de son côté, identifie ce qu'il est avec ce qu'il fait être par communication de lui-même" Moingt, I, 364s. Según este mismo autor (ibidem, 366), "Du Père au Fils en effet, et sans doute encore du Fils à l'Esprit Saint, il y a dégradation et dépendance quant à l'acte de subsister".

81 Texto de Kroymann. Según 7, 5, el Sermo es substantivo (alguna substancia) por la propiedad de la substancia.

82 Según 7, 6, no puede carecer de substancia el que de tanta substantia processit et tantas substantias fecit. Según 7, 9, el emitido de la substancia del mismo Dios no puede carecer de substancia.

83 Según 3, 1, la unidad deriva de sí misma la Trinidad, lo que no destruye la unidad, sino que la administra (economía).

84 Respecto a que el "Espíritu de Dios vendrá sobre ti" (Lc 1, 35), aclara Tertuliano que no dice directamente 'Dios', porque se trata de una porción del todo que pasará (cessura) al nombre del Hijo $(26,3)$. Evans traduce así: "he wished there to be understood an assignment of the whole which was to go to the Son's account". Tertuliano complementa después diciendo que el Espíritu es la substancia del Sermo y el Sermo es la operación del Espíritu: ambos son uno $(26,4)$. "Or le rapport du Fils (et de l'Esprit Saint) au Père est expimé dans le même vocabulaire: ils sont unis: cohaerentes, dans une société indissoluble; conjunctio, conexus, societas nominum, qui 
(modulo), en traducción de Scarpat $(9,1)^{85}$. El Padre es invisible por la plenitud de la majestad ${ }^{86}$, pero el Hijo es visible por la medida (modulo) de la derivación. Así como no podemos contemplar el sol en la totalidad (summam) de la substancia, sin embargo, toleramos su rayo por la temperatura de la porción que se alarga (inde porrigitur ${ }^{87}$ ) hasta la tierra $(14,3)$. Las tentativas de Tertuliano para expresar la distinción en la unidad no son directamente cualitativas, porque es el mismo estatus. El Padre y el Hijo son lo mismo (unum en Jn 10, 30), son el único Dios ${ }^{88}$. Atañen más bien a la cantidad, tratando de reflejar la concatenación, el proceder el uno del otro. Si el Padre es ingénito (innatus), el Hijo es unigénito $^{89}$, y por eso tiene la substancia del Padre, es Dios ${ }^{90}$. Aunque el vocabulario de Tertuliano respecto a la Trinidad sea insatisfactorio, sin embargo, mantiene claramente los dos polos del misterio del Dios cristiano: la distinción de las personas y la unidad de la única substancia, dentro de la atmósfera subordinacionista prenicena. Como dice al final de su tratado, ahora son creídos tres personas, conocidos en sus propios nombres y personas, que constituyen el un solo Dios. Esta es la novedad del Evangelio. Si Tertuliano tuvo clarividencia, al parecer, para llegar a hablar de dos substancias sin mezcla en una única persona de Cristo ${ }^{91}$,

se «distribue» au plan de l'être en «totalité» et en "portion», de telle manière que cette structure de être se redouble aussitôt dans une 'administration' hiérarchique de l'indivisible Monarchie divine: au Père revient la principalitas, l'imperium, au Fils le ministerium, l'officium, l'obsequium" MoINGT, II, 420. "L'idée de consubstantialité chez Tertullien ne doit pas être cherchée dans la théorie stoïcienne du pneuma et du corpus [...], ni dans le concept unius substantiae [...] Elle est exprimée par le mot portio (auquel est associé modulus), qui n'a donc pas le sens quantitatif soupçonné par plusieurs [...], mais celui de "participation"” MoINGT, I, 46. "Esta (portio) no significa propiamente «parte» (pars); el Hijo no es una "parte» de la substancia divina sino que "participa» en ella" Grillmeier, Cristo I, 271.

85 "Im Umfang" traduce Sieben. "Le modulus qui distingue le Père et le Fils ne signifie donc pas le partage de la substance totale en une partie plus grande et une partie plus petite, mais la différence de deux modes de subsister, pour l'un sous la raison d'être par soi le tout indivis de la divinité, et pour l'autre d'y avoir part et d'appartenir à ce tout” MoIngt, III, 955s. Cf. Moingt, III, 940-957. Cf. 16, 6.

87 Véase 23, 12; Apologeticum, 21, 12 (extenditur, ut lumen de lumine accensum).

88 Cf. por ejemplo la regla de la fe $(2,1)$. El Hijo de Dios, en cuanto es Dios, es tan omnipotente como el Padre (cf. 17, 4). Cf. 19,$6 ; 7,1$.

90 Ex Deo Deus $(15,5)$.

91 De paso afirma el alma de Cristo (30, 2; cf. 5, 5; 16, 4). 
también la tuvo para formular una única substancia en Dios, aunque utilice expresiones deficientes. Y a propósito de la no mezcla en la encarnación, afirma Tertuliano que el Sermo y Espíritu de Dios se reviste de carne, pero no se transfigura en esta, porque Dios, al ser eterno, es inmutable e intransformable (informabilem) $(27,6)^{92}$.

\section{c. Hacia los orígenes del sermo}

Vista la actual unidad entre el Padre y el Hijo y si se prescinde de que el Hijo es Dios, por tanto eterno ${ }^{93}$ e inmutable, nos podemos preguntar, junto con Tertuliano, por la disposición de Dios hasta la prolación del Hijo por el Padre antes de la creación $(5,1)$. Ciertamente, todo fue creado por el Padre mediante el Hijo; toda la economía es por el Hijo: no solo las obras del mundo sino todo lo que después se ha realizado. Porque el Padre desde el principio (a primordio) ama al Hijo y ha puesto todo en sus manos $(16,1 \mathrm{~s})^{94}$. En el capítulo 5 , al comenzar a examinar

92 Así también el Hijo, igual que el Padre, es impasible e in-com-pasible en cuanto Dios (29, 5s). Sobre induere carnem, cf. A. Viciano, Cristo salvador y liberador del hombre. Estudio sobre la soteriología de Tertuliano (ed. Univ. de Navarra, Pamplona 1986) 131s.

93 Cf. 27, 6s. Además también se le aplica al Hijo el nombre del Padre 'Qui est', porque mucho son llamados hijos y no lo son $(17,2$ s). Comenta Scarpat ad 1. c.: "Molti sono figli di Dio, anzi tutti figli di Dio, ma nessuno lo è ab aeterno come il Cristo". «Si Tertullien, quand il traite de la Trinité n'affirme pas plus nettement l'éternité du Fils et de l'Esprit, c'est vraisemblablement parce qu'il ne concevait aucune crainte à ce sujet et n'avait même pas l'idée qu'on put s'inquiéter” MoINGT, III, 1069. No hay medida de tiempo en la eternidad. "Son concept d'origine ne lui permettait pas d'exprimer positivement, au plan métaphysique, l'existence éternelle des Personnes procédantes; sa doctrine de la création, ses concepts de temps et d'éternité lui permettait de la concevoir négativement, par l'exclusion de toute limite temporelle; la liaison qu'il mettait entre la disposition créatrice et l'origine de ces Personnes l'obligeait à repousser de celle-ci tout ce qui aurait pu imputer à celle-là une 'excitation occasionnelle' et une «mesure de temps»". Moingt, III, 1071. Muy interesante resulta la intuición de Moingt sobre la eterna Trinidad económica de Tertuliano. "Dans sa pensé c'est une libre exigence de la puissance et de la bonté de Dieu de vouloir être connu et aimé: c'est une semblable nécessité, exempte de toute 'motivation adventrice et extérieure', qu'il atribue a la procession du Verbe et de l'Esprit". Moingt, III, 1073. Puede verse la argumentación de J. Wolinski "De l'économie à la théologie [III siècle]", 198s, en B. Sesboüé-J. Wolinski, Le Dieu du Salut [Histoire des Dogmes I], Desclée, Paris 1994) 177-233, respecto a la eternidad del origen del Hijo.

94 Cf. $16,7$. 
todo lo del Hijo, topa Tertuliano con un texto hebreo de Gn 1, 1 que dice: en el principio Dios se hizo para sí un Hijo. Lo descarta porque no es seguro; se dejará conducir por argumentos tomados de la misma disposición de Dios antes de la constitución del mundo hasta la generación del $\mathrm{Hijo}^{95}$. Por lo demás ni siquiera entonces estaba solo, porque tenía en sí mismo la razón, el $\lambda o ́ \gamma o s$, el Sermo. Dios era racional también antes del principio ${ }^{96}$. Aunque Dios todavía no había emitido su Sermo, pero lo tenía consigo tácitamente, al pensar y disponer lo que iba a decir. Como en el hombre, imagen y semejanza de Dios, en el que el pensamiento va siempre acompañado de la palabra y esta del pensamiento. Possum itaque non temere praestruxisse et tunc Deum ante universitatis constitutionem solum non fuisse, habentem in semetipso proinde rationem et in ratione sermonem quem secundum a se fecerat agitando intra se $(5,7)^{97}$.

Hechas estas elucubraciones intelectuales ${ }^{98}$, Tertuliano pasa al texto de Pr 8, 22-30 y aplica la Sabiduría a la razón y Sermo. Primeramente la Sabiduría es creada initium viarum in opera sua $(\operatorname{Pr} 8,22)$ y generada $(\operatorname{Pr} 8,25)$ en la mente divina. Después asiste a Dios en la creación con mutuo gozo. Cuando Dios quiso que fuera realizado el universo, que ya estaba pensado, dispuesto y hecho en su mente por el Sermo, lo profirió ${ }^{99}$ (6, 1-3). Cuando Dios dice "hágase la luz", toma su forma y belleza, sonido y voz ${ }^{100}$. Este es el nacimiento completo (perfecto) del Sermo, cuando procede de Dios. Conditus (Sermo) ab eo primum ad cogitatum

95 "Tertullian does not really think that the Father ever existed without the Son: as he says almost immediately, ceterum ne tunc quidem solus. But he is unable to rid himself of the idea of a priority of the Father, at least in thought, or to dissociate it from some sort of time sequence". Evans ad l. c.

96 La razón tiene cierta prioridad sobre el Sermo, porque este está constituida de razón. Quia non sermonalis a principio sed rationalis Deus etiam ante principium $(5,3)$.

97 Cf. Adv Herm, 18, 2 (4).

98 Praestruxisse. "La démonstration scripturaire des chapitres VI et VII recouvre exactement la démonstration rationelle du chapitre $V$; on y retrouve la même distribution en deux époques, avant et après le temps, et rien d'autre", MoINGT, III, 1052.

99 Para que fuera realizado por el mismo Sermo que las había pensado, etc.

100 Según 12, 5, Primo quidem nondum Filio apparente: 'Et dixit Deus: fiat lux, et facta est', ipse statim sermo, 'vera lux quae illuminat hominem venientem in hunc mundum' et per illum mundialis quoque lux. Scarpat traduce statim, siguiendo la baja latinidad, por: en aquel preciso momento. 
in nomine sophiae ${ }^{101}$, dehinc generatus ad effectum ${ }^{102}$, exinde eum (Dios) Patrem $^{103}$ sibi faciens, de quo procedendo filius factus est... primogenitus... et unigenitus $(7,1)^{104}$. Es el único engendrado de Dios, propiamente del seno de su corazón (cf. Sal 44, 2; 2, 7; 109, 3) (7, 1s). Nuestro autor vuelve a repetir los versículos de Pr sobre la Sabiduría creada y generada. La Sabiduría 'creada en vista de sus obras' coincide con que todo ha sido hecho por el Sermo (Jn 1, 3; cf. Sal 32, 6). Luego se trata de la misma potencia bajo el nombre de sabiduría o el apelativo de sermo, el Sermo que ha sido hecho Hijo de Dios, procediendo del cual fue generado $(7,4)$. Y el Sermo de Dios no carece de substancia, es Dios (Jn 1, 1; Flp 2, 6), es la segunda persona $(7,5-9)$. Detengámonos un momento. Queda claro que lo primero es crear y engendrar el Sermo en la mente divina y, mediante este, crear en la misma mente divina el universo, y después, cuando Dios quiere crear el universo en su propia consistencia, Dios profiere el Sermo. En que Dios diga 'Hágase la luz' (primera palabra de Dios en $\mathrm{Gn}$ ), lo que es connotado como el nacimiento completo del Sermo, sigue aplicando Tertuliano la comparación con la palabra humana ${ }^{105}$. En la frase conditus ad cogitatum..., dehinc generatus ad effectum ${ }^{106}$, nuestro autor sigue el ritmo de las citas de $\operatorname{Pr} 8,22.25$, que está aplicando a la Sabiduría. Y la generación trae la relación padre e hijo. Luego creo que tanto las elucubraciones como las citas de Pr influyen en Tertuliano para

101 Deus condidit me initium viarum suarum.

102 Cum pararet caelum, aderam illi.

103 Siguiendo a F y M.

104 Cf. 11, 1, etc. Padre e Hijo, distintos entre sí, se implican mutuamente. Cf. p. e. 10, 2-6; 22, 4; 31, 3. "La Ratio-Sermo ne reçoit donc pas sa nature divine de sa génération ou de sa prolation en ce monde -elle l'a déjà en Dieu-, mais elle en reçoit le nom de Fils. Ce que signifie qu'on ne l'appelle Fils que dans sa relation à la création et à son incarnation”. B. PIAUlT, "Tertullien a-t-il été subordinatien?", (RevSPhTh 47, 1963) 181-204, 196.

105 "L'analogie du discours d'une part, l'analyse de la substance divine d'autre part montre qu'il y a en Dieu de tout temps un Sermo, qui est d'une part distinct, d'autre part esprit subsistant, donc une seconde chose. Mais la notion de personne est fournie par le dialogue des «voix». Or le Sermo reçoit la voix quand il est proféré par Dieu” MoINGT, II, 1060. “C'est que la personnalité reste liée pour lui à l'élement de la manifestation: c'est un sujet qui se fait voire et entendre, qui se pose dans l'être-là", Moingt, II, 1060. Las oscuridades de Tertuliano vienen de haber elaborado insuficientemente los conceptos filosóficos.

106 Según Moingt III, 1056, "Il s’agit dans le premier cas de la génération active, de l'acte paternel qui précède la conception de l'enfant; et dans le second cas, de la génération passive, de la 'naissance' de l'enfant qui est 'achevée' par la sortie du sein". 
el uso de sus expresiones: nativitas perfecta, dehinc generatus. Sobre todo hay que tener en cuenta que la mirada de Tertuliano sobre los comienzos es desde la creación, desde la economía. Vistos estos condicionamientos y el pensamiento general del autor, no me parece acertada la interpretación de los tres estadios de la formación del Sermo que hace Orbe ${ }^{107}$ respecto a 7,1 , etc. ${ }^{108}$.

107 Cf. A. Orbe, p. e. "Elementos de teología trinitaria en el Adversus Hermogenem cc. 17-18, 45”, Gregorianum (39, 1958) 706-746; Hacia la primera teología de la procesión del Verbo. Estudios Valentinianos I (Analecta Gregoriana 99, Univ. Gregoriana, Roma 1958) 153-164; 351-362; La teología dei secoli II e III. Il confronto della Grande Chiesa con lo gnosticismo. I: Temi veterotestamentari (Univ. Gregoriana, Roma 1995) 123-127; 170-176; Estudios sobre la teología cristiana primitiva (Fuentes Patrísticas. Estudios 1, Ciudad Nueva-Pontificia Univ. Gregoriana, Madrid-Roma 1994), 3-5; 26-29; 142-153; "Introduzione”, en A. Orbe-M. Simonetti, Il Cristo I: Testi teologici spirituali del I al IV secolo, Fondazione Lorenzo Valla, Milano ${ }^{3} 1990$, VII-XCV.

108 Concluye moingt, Théologie Trinitaire, III, 1060s: “En définitive, il n’y pas trois étapes de la formation du Sermo, il n'y en a même pas deux. Il y a un "commencement» intérieur, illimité et achevé en lui-même, et un terme, qui en est l'extériorisation. Avant le temps et de tout temps il y a l'acte générateur du Père, instantanément efficace et 'parfait' comme chacun de ses actes créateurs, auquel correspond la naissance du Sermo comme être réel et distinct, et qui est achevée en elle-même au plan de l'être 'sitôt' qu'elle est. Et il y a dans le temps et au commencement du temps un second acte du Père, qui ne consiste pas à parfaire l'être du Sermo, mais à l'exprimer; et à cette expression correspond 'l'achèvement' de la naissance du Fils, qui n'est pas la finition de son être, mais sa sortie de Dieu et son apparition au monde. Cela fait deux instants, deux actes du Père, deux 'passions' du Fils; cela ne fait pas deux états ontologiques du Sermo, si ce n'est deux manières d'ètre: l'être en Dieu et pour Dieu, et l'être-là auprès du Père dans le monde”. Habría, pues, una formación progresiva del Sermo, pero de orden intelectual y no substancial. "La prolation apporte donc au Sermo un 'achèvement' réel, qui est de l'ordre du discours: il devient Parole efficace et Parole parlé" Théologie Trinitaire, III, 1060 s. Según G. Uríbarri Bilbao, La emergencia de la Trinidad inmanente: Hipólito y Tertuliano ([Publicaciones Univ. Pont. Comillas Madrid], UPCO, Madrid 1999), la posición de Práxeas, después de la refutación de Hipólito a Noeto, obliga a Tertuliano a atisbar el Sermo eterno (anterior al tiempo) en Dios, como respuesta implícita a la afirmación de Praxeas: Itaque post tempus Pater natus et Pater passus, ipse Deus Dominus omnipotens Iesus Christus praedicatur $(2,1)$, etc. Con provecho puede leerse su análisis a Prax. 5-8: Una lectura desde la retórica clásica ( cap. 2, III). J. Alexandre, Le Christ de Tertullien ([Jésus et Jésus-Christ, 88], Desclée, Paris 2003) destaca el sentido de unidad y continuidad de Tertuliano, quien está centrado en Cristo según la eterna disposición salvífica de Dios. Pretende contraponerse a Moignt (p. e. 266), acentuando la concepción estoica de la acción, del desarrollo, 
En 8, 1 comienza a hablar nuestro autor de la prolación (probole ${ }^{109}$ ) del Sermo de Dios, que es la de la verdad y no la de la herejía de Valentín, que separaba del Padre los eones, los cuales llegaban a desconocerlo. El Hijo conoce al Padre, el seno de este; nos lo expone, hace en todo su voluntad, es el Espíritu que está en Dios (1 Co 2, 11). Por tanto el Sermo siempre está en el Padre $(\mathrm{Jn} 1,1)^{110}$. Emitido por el Padre, pero nunca separado de él. Esta prolación es custodia de la unidad. Como el rayo del sol, etc. Todo origen es generador de lo que proviene de ese origen, su progenie, su segundo. Mucho más el Sermo de Dios que recibe el nombre de Hijo (8, 1ss). En 19, 1ss, a propósito de que Dios solo extendió el cielo (Is 44, 24), muestra que le asistía la Sabiduría, Sermo, Hijo. Y agrega que en el principio existía el Sermo, en el cual principio fue emitido (prolatus) por el Padre. El Padre no tiene inicio (en ese sentido no es primero ${ }^{11}$ ), porque siendo innato, no es proferido por nadie (19, 6). Hasta aquí lo principal de lo que Tertuliano dice sobre los orígenes del Sermo, interpretado dentro del margen general del pensamiento de nuestro autor.

\section{d. A modo de conclusión}

Concluimos, pues, que el pensamiento trinitario de Tertuliano constituye una imponente refutación del monarquianismo de Práxeas: no es el Padre el que padeció en la cruz. Pareciera no dar puntada sin hilo. Su centro es mostrar que el Hijo (el Sermo) es un otro, pero siempre unido, respecto a la persona del Padre. El problema es trinitario, alargándose hasta el Espíritu: tres personas de una misma substancia. Pues somos bautizados tres veces: en el Padre, en el Hijo y en el Espíritu. La persona del Hijo es una realidad substantiva, distinta del Padre, pero no otro Dios. "Persona" es un vocablo bastante usado, y a veces con pasión. Tertuliano persigue a Práxeas aun en la encarnación, su nuevo refugio. Así declara una vez: dos substancias sin mezcla en la única persona de

respecto a unidad y pluralidad, pero no convence del todo. Puede verse la ácida recensión de P. MATTEI, RHE 101 (2006) 170-175.

109 Cf. Orbe, Hacia la primera teología de la procesión del Verbo, 519-531.

110 Sermo ergo est in Patre semper, sicut dicit: 'Ego in Patre', et apud Deum semper, sicut scriptum est: 'Et sermo erat apud Deum', et numquam separatus a Patre aut alius a Patre quia: 'Ego et Pater unum sumus' (8, 4).

111 Qui solus fuit semper, ordinem habere non potuit (19, 6). Primum scilicet omnium sermo $(19,6)$. Cf. 8, 7; 18, 2. 
Cristo, cada una con su operación propia. Tenemos, pues, el comienzo de estas dos fórmulas (la trinitaria y la de la Encarnación) que deberán ser profundizadas durante siglos ${ }^{112}$. Pero, junto con ellas, nuestro autor utilizará también otros términos que serán después abandonados. Se mueve, entonces, en una teología tentativa, donde no todas las expresiones fueron retenidas como adecuadas. La fuente (toda la substancia, plenitud de la majestad) es el Padre, desde donde deriva el Hijo, y a través de este, el Espíritu. Padre e Hijo se implican mutuamente. Presenta una Trinidad jerarquizada (segundo y tercero), aunque el Padre y el Hijo son Dios, son del mismo estatus. Así el Padre, por ser la fuente, es mayor. El Padre es invisible, el Hijo puede ser visible (en sueño y enigma como en las teofanías del A. T.; en la carne que vieron y tocaron los apóstoles). El mayor problema subordinacionista, propio de apologetas prenicenos, se da en torno a algunas expresiones sobre los orígenes del Hijo, que se deberían interpretar dentro del conjunto de su teología trinitaria, como hemos tratado aquí. Creo que no se planteó directamente el problema del Hijo en la eternidad divina, sin perspectiva económica. Por eso que el origen del Hijo gira, en fin de cuentas, en torno a la creación, siguiendo los textos bíblicos y la metáfora de la palabra humana que es completa cuando se pronuncia. Pero su punto de partida es que Dios siempre ha sido racional. Por lo demás, su teología trinitaria es riquísima y se expresa no solo en la sistematización de Tertuliano sino en los riquísimos textos bíblicos con que la ilustra. Ha equilibrado la monarquía con la economía. Ahora Dios, en forma nueva es creído uno por el Hijo y el Espíritu. Tertuliano representa un muy buen comienzo para la teología latina trinitaria. Dio un gran paso en pensar la Trinidad y encarnación. Se aproximó a las fórmulas de los concilios futuros, pero obviamente su pensamiento no llegó al fondo de lo que es la persona y la substancia $^{113}$. Otras iniciativas de su vocabulario son menos satisfactorias y no prosperaron. Se mueve en la atmósfera subordinacionista de la teología prenicena, anterior al consubstancial. Su refutación de los patripasianos

112 Hay autores actuales que ven inconvenientes en el uso de persona para la Trinidad. Cf. S. Zañartu, "Algunas reflexiones de conjunto sobre el misterio del Dios uno y trino", Teología y Vida 42(2001)468-489, lo que también puede leerse, junto con mis otras publicaciones, en Internet: szanartu.wordpress.com.

$113 \mathrm{Al}$ respecto puede verse, S. Zañartu, "Reflexiones sobre la fórmula dogmática del concilio de Calcedonia”, Teología y Vida 39 (1998) 155-184. S. Zañartu, "El concilio de Constantinopla I y el proceso previo. Algunas anotaciones", Teología y Vida 48 (2007) 471-497. 
es contundente. Contra ellos utiliza innumerables citas bíblicas con lógica implacable. Fue fiel a la escritura y a la regla de la fe que prescriben respecto a todas las novedades de los herejes ${ }^{114}$.

114 Moingt III, 1084, concluye: “Ainsi jugée, sa théologie est absolument irreprochable”. "S’il paraît subordonner le Fils au Père, c'est parce qu'il le considère d'habitude dans ses missions et son incarnation, en sa qualité d'envoyé et de serviteur, mais il attribue la même divinité toute-puissante à l'un et à l'autre". (MOINGT III, 1085). "Praxéas ne se préoccupait pas de la "disposition de Dieu» avant le commencement du monde; par contre il dénonçait une división de la substance dans le fait que le Fils «sort» du Père au commencement. Cela amenait Tertullien à parler des "prolations» dans la même perspective de temps et d'exteriorité, et ne l'entrainaît point à scruter les origines éternelles comme telles du Fils et de l'Esprit. Son silence n'est pas négation, ni même méconnaissance. Il signifie simplement qu'une certaine question ne s'était pas encoré posée dans la conscience des théologiens, et ne pouvait pas se poser avant que la Trinité n'ait été proprement conçue dans son immanence substantielle, ce qui a été fait en parti grâce au travail de Tertullien”. Moingt III, 1086. El texto "Fuit tempus, cum [...] et filius non fuit" de Adv Herm 3, 4, (4) junto con Dominus y iudex, está en referencia a la creación por la que comienza a ser Padre de Adán, juez del transgresor y Señor de la creación. No se necesita, por tanto, que la materia sea eterna. Cf. Moingt III, 1029-1032. 